\title{
OBSERVATIONS ON THE GASTRIC ACIDITY DURING THE FIRST MONTH OF LIFE
}

BY

\author{
R. A. MILleR, B.A., M.D., M.R.C.P.*
}

(From the Royal Infirmary, Edinburgh)

Systematic observations on the gastric acidity throughout the first month of life have been undertaken, as no records of its behaviour during that period have been noted in the literature.

In order to investigate the acidity, the fasting juice of fifty healthy, mature breast-fed infants was withdrawn from the stomach seven hours after a feed, daily for the first ten days of life. Thereafter, from the eleventh to the

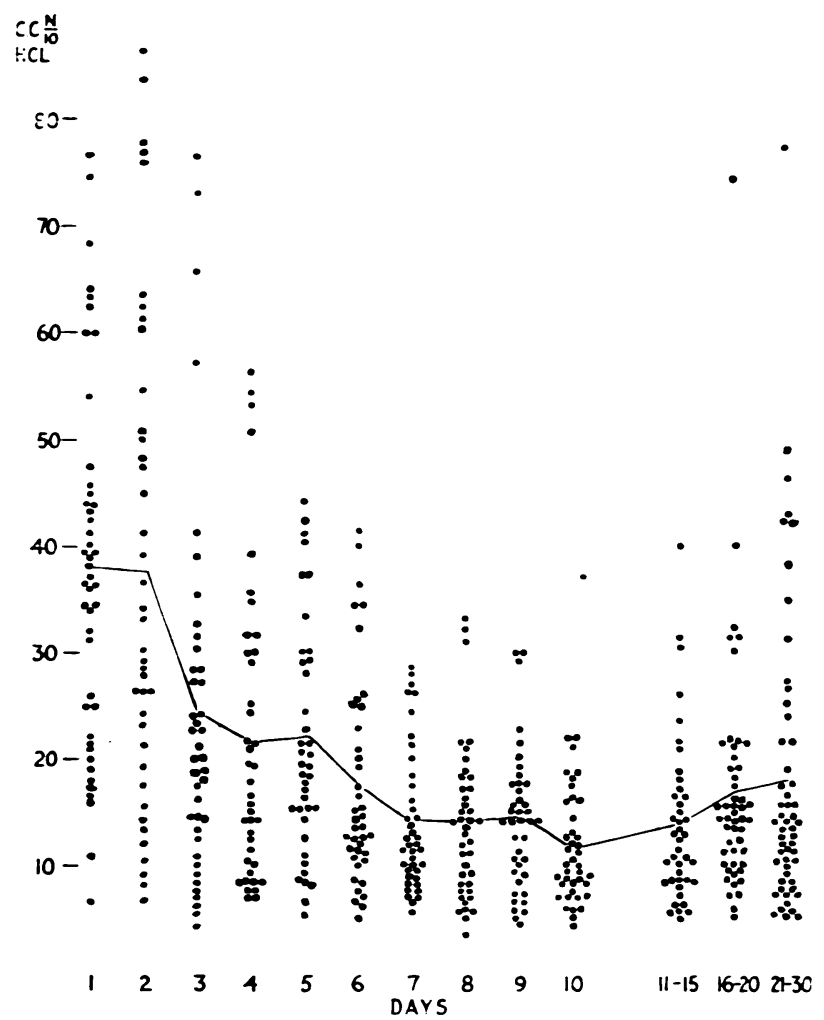

Fig. 1.-The total acidity of the fasting juice during the first month of life, expressed in c.c. $\mathrm{N} / 10 \mathrm{HCl}$ per 100 c.c. stomach contents.

* Working under the auspices of the Kirk Duncanson Research Fellowship of the Royal College of Phy sicians, Edinburgh. 


\section{GASTRIC ACIDITY DURING THE FIRST MONTH OF LIFE 23}

thirtieth day, the fasting juices were taken from any healthy infant which might be detained in hospital. The following method was used in examining the specimens quantitatively for free and total acidity: 1 c.c. fasting juice when available was titrated with $\mathrm{N} / 70 \mathrm{NaOH}$ and the end points determined with Töpfer's reagent and phenolphthalein respectively. The results are given in fig. 1 .

The normal trend of gastric acidity and its causation

The composite figures showing the steady decline of the total acidity of the fasting juice from birth until the tenth day of life give a true impression of the behaviour of each individual infant, particularly when the infant had a high acidity during the first or second day. A similar decline in the gastric acidity after birth has not been recorded in the literature ; but Cutter (1938), after reviewing gastric acidity during the first four years of life and making a few observations himself, suggests that there is probably a fall in the acidity of the gastric secretion after the tenth day of life.

TABLE 1

\begin{tabular}{|c|c|c|c|c|c|c|}
\hline CASE & DAY & FASTING JUICE & $\begin{array}{c}1 \text { HOUR } \\
\text { AFTER FOOD }\end{array}$ & $\begin{array}{l}1 \frac{1}{2} \text { HOURS } \\
\text { AFTER FOOD }\end{array}$ & $\begin{array}{c}\text { BODY } \\
\text { LB. }\end{array}$ & $\begin{array}{l}\text { WEIGHT } \\
\text { OZ. }\end{array}$ \\
\hline I & $\begin{array}{r}2 \\
3 \\
4 \\
5 \\
6 \\
7 \\
10 \\
14\end{array}$ & $\begin{array}{l}70 \cdot 7 \\
25.0 \\
11 \cdot 4^{*} \\
14 \cdot 3 \\
11.4 \\
7 \cdot 2 \\
4.3 \\
10.0\end{array}$ & $\begin{array}{l}45 \cdot 7 \\
17 \cdot 4 \\
14 \cdot 6 \\
18 \cdot 6 \\
17 \cdot 4 \\
25 \cdot 0 \\
10 \cdot 7 \\
14 \cdot 3\end{array}$ & $\begin{array}{r}53 \cdot 6 \\
8 \cdot 6 \\
9.7 \\
38 \cdot 6 \\
16 \cdot 6 \\
- \\
-\end{array}$ & $\begin{array}{l}6 \\
6 \\
6 \\
7 \\
7 \\
7 \\
7 \\
7\end{array}$ & $\begin{array}{c}10 \\
10 \\
14 \\
0 \\
0 \frac{1}{2} \\
1 \\
1 \frac{1}{2} \\
9\end{array}$ \\
\hline II & $\begin{array}{r}2 \\
3 \\
4 \\
5 \\
6 \\
7 \\
10 \\
14\end{array}$ & $\begin{array}{r}35 \cdot 7 \\
18 \cdot 5 \\
11 \cdot 4 \\
10 / 0 \\
9 \cdot 6 \\
7 \cdot 1 \\
10-0 \\
7 \cdot 1\end{array}$ & $\begin{array}{r}28 \cdot 6 \\
15.6 \\
14.6 \\
9.0 \\
11.4 \\
17 \cdot 1 \\
12.9 \\
22.9\end{array}$ & $\begin{array}{r}37 \cdot 7 \\
9 \cdot 1 \\
12 \cdot 9 \\
19 \cdot 3 \\
- \\
- \\
-\end{array}$ & $\begin{array}{l}7 \\
7 \\
7 \\
7 \\
7 \\
7 \\
7 \\
7\end{array}$ & $\begin{array}{l}3 \\
3 \\
1 \\
1 \\
0 \frac{1}{2} \\
2 \\
3 \\
4 \frac{1}{2}\end{array}$ \\
\hline III & $\begin{array}{r}2 \\
3 \\
4 \\
5 \\
6 \\
7 \\
10 \\
14\end{array}$ & $\begin{array}{r}60 \cdot 6 \\
21 \cdot 1 \\
15 \cdot 6 \\
7 \cdot 1 \\
11 \cdot 4 \\
7 \cdot 1 \\
8 \cdot 6 \\
17 \cdot 1\end{array}$ & $\begin{array}{c}55 \cdot 7 \\
15 \cdot 0 \\
16 \cdot 6 \\
21 \cdot 4 \\
24 \cdot 6 \\
6 \cdot 4^{*} \\
17 \cdot 9 \\
35 \cdot 7\end{array}$ & $\begin{array}{c}40-0 \\
14 \cdot 3 \\
10-0 \\
14 \cdot 6 \\
- \\
- \\
-\end{array}$ & $\begin{array}{l}6 \\
6 \\
6 \\
6 \\
6 \\
6\end{array}$ & $\begin{array}{c}2 \frac{1}{2} \\
-2 \frac{1}{2} \\
5 \\
7 \\
6 \\
{ }^{8 \frac{1}{2}}\end{array}$ \\
\hline
\end{tabular}

* Blood present

The most likely explanation of this initial fall in acidity is that some gastrogenic hormone is supplied to the infant in utero, either from the mother or the placenta. The influence of this assumed secretogogue upon the infant is most marked during its first two days. Then it rapidly vanishes, leaving the infant to control its own gastric digestion on or before the tenth day of life. After the tenth day the gastric acidity slowly increases throughout the remaining 
days of the first month, but does not attain such a high level as during the first five days after birth. From this fact, it might be assumed that during the first month the infant's digestion is best when it is under six days old. In an attempt to confirm this, three newborn infants were given eight test-meals during their first two weeks. The test-meal consisted of equal parts of breast-milk and water, and amounted to 60 minims per pound body weight. The results are shown in table 1 . They express in c.c. $\mathrm{N} / 10 \mathrm{HCl}$ the total acidity in 100 c.c. gastric contents. In table 1 , the test-meals show that the reaction of the gastric secretion to the feed is as was anticipated, i.e. the lower the acidity of the fasting juice the poorer was response of the gastric secretion to a test-meal.

\section{The normal daily range of gastric acidity}

The difference between the maximum and minimum limit of total acidity gradually decreases with age, until, on the tenth day, it is only 18 c.c. $\mathrm{N} / 10 \mathrm{HCl}$. This is due to the fact that infants start life with a varying degree of reserve in their gastric secreting power which is probably completely exhausted by the tenth day. Thereafter, the infant exerts its own influence over gastric digestion so as to maintain the basic level for gastric acidity, and later to increase it.

There is at first great variation between the maximum and minimum amounts of free acidity, but after the second day of life the free acidity falls to zero in most cases. The average free acidity is about 20 c.c. less than the average total acidity, as will be seen in table 2 , where the acidity is expressed in c.c. $\mathrm{N} / 10 \mathrm{HCl}$ per 100 c.c. gastric contents.

TABLE 2

\begin{tabular}{cccc}
\hline DAY & NO. OF CASES & FREE ACID & TOTAL ACID \\
\cline { 2 - 3 } \cline { 4 - 4 } 1 & 45 & $17 \cdot 2$ & $38 \cdot 0$ \\
2 & 40 & $15 \cdot 4$ & $37 \cdot 9$ \\
3 & 41 & $4 \cdot 5$ & $24 \cdot 6$ \\
4 & 40 & $1 \cdot 0$ & $21 \cdot 7$ \\
5 & 40 & $0 \cdot 7$ & $22 \cdot 3$ \\
6 & 40 & $0 \cdot 2$ & $17 \cdot 6$ \\
7 & 40 & $0 \cdot 4$ & $14 \cdot 2$ \\
8 & 41 & $0 \cdot 0$ & $14 \cdot 2$ \\
9 & 40 & $0 \cdot 0$ & $14 \cdot 4$ \\
10 & 40 & $0 \cdot 0$ & $11 \cdot 7$ \\
$11-15$ & 41 & $0 \cdot 7$ & $13 \cdot 8$ \\
$16-20$ & 50 & $1 \cdot 0$ & $16 \cdot 9$ \\
$21-30$ & 45 & $2 \cdot 1$ & $18 \cdot 0$ \\
& & & \\
\hline
\end{tabular}

\section{Day of maximum acidity}

The maximum acidity in the fasting juice is probably reached within twentyfour hours of birth. In some instances, however, the maximum was reached on the second day. This was due to the fact that the fasting juice was taken so soon after birth that the flow of gastric secretion had not been given time to reach its maximum. Therefore, the maximum average free and total acidity quoted on the first day of life as 17.2 c.c. and 38.0 c.c. respectively is an underestimation. Partly to eliminate this error, the average maximum acidity was calculated 
using the highest reading for each infant during the first forty-eight hours. The figures thus obtained are 21.6 c.c. $\mathrm{N} / 10 \mathrm{HCl}$ free acidity and 45.9 c.c. $\mathrm{N} / 10 \mathrm{HCl}$ total acidity. This degree of acidity is astonishingly high, for it is equivalent to that of a healthy adult, and does not reappear in childhood until the age of three years (Levinson and MacFate, 1937). To explain the phenomenon it is necessary to compare the infant's gastric acidity with that of its mother at the time of delivery. Unfortunately, this is extremely difficult because the mother's gastric residue almost always contains bile and occasionally blood, and it is also probable that the mental and physical strain during labour disturbs the normal gastric secretion. However, from observations made by Strauss and Castle (1932) on twenty-four women during their pregnancy and after parturition, it can be concluded that the mother's gastric acidity rises towards normal adult figures at the time of delivery. This is substantiated by Krahmer-Peterson (1939), who stated that the gastric secretion, subnormal during pregnancy, actually returns to the normal adult concentration in almost all cases within a few weeks after parturition. Thus it may be concluded that it is possible for the gastric acidity of the infant to bear a very close relationship to that of the mother at birth.

\section{Achlorhydria in the newborn}

The relationship between the mother's gastric secretion and her infant's at birth is further emphasized by the fact that the percentage of mothers with achlorhydria during pregnancy is identical with the number found in mature infants at birth. Achlorhydria was present in three out of twenty-four mothers (Strauss and Castle, 1932), and in six out of fifty infants during the present investigations. These findings are of interest as Faber (1927), after reviewing the question of achlorhydria in children, did not believe that congenital achlorhydria existed, a view shared by the majority of investigators (Tangl, 1906; Hess, 1913; Griswald et al., 1925; and Pollitzer, 1921), who believed that free acid was always present in the fasting juice of the unfed infant at birth.

\section{Correlation of weight progress with gastric acidity}

The relationship between the gastric acidity and weight progress of the infant was studied in the fifty infants during the first ten days of life, and there was found to be no connexion between the two at any stage of development. This suggests that it is not essential for infants to have a high gastric acidity in order to maintain their weight and health; that the variable high acidity at birth is merely a provision of nature to maintain an adequate digestive mechanism from birth until the infant's own power of digestion is sufficiently developed. On the other hand, a low gastric acidity does not mean that the infant's digestive powers are subnormal, for the infant in such circumstances can remain in good health and gain weight normally.

The volume and character of the specimens obtained

Out of the 707 specimens tested 73 had to be rejected because they contained either bile, blood or milk. The presence of these substances did not 
indicate that disease was present, nor did it mean that there was a delay in emptying of the stomach. In some instances, in which milk was found, the infant had been accidentally fed a short time before the fasting specimen had been obtained.

The amount of fasting juice bore a close relationship to the degree of acidity in that, during the first two days of life when the acidity was highest, the volume was at least 1 to 3 c.c., whereas during the remaining part of the month when the acidity was lower the volume decreased to 0.5 c.c. or less. This can be explained by the fact that the degree of acidity normally varies directly as the rate of secretion (Ihre, 1939). Nevertheless, the amount of gastric residue is partly dependent upon the motility of the stomach, which may conceivably vary during the first month of life. If this is so, it is unlikely that it is responsible for the large amounts of fasting juice during the first forty-eight hours of life, provided the following statement made by Davidsohn (1921) is correct; " the motility of stomachs in infancy increases or diminishes as the gastric acidity rises or falls.'

\section{Discussion}

There seems to be an extrinsic factor, an intrinsic factor, or a combination of both responsible for the fluctuation of the gastric acidity during the first month of life. If it is extrinsic in origin it may be supplied to the infant from the maternal circulation in utero, or in its food after birth. The latter source of a gastrogenic substance is unlikely, for human milk and cow's milk have been tested for hormones by Block (1936) and also by Weisman et al. (1935) with negative results. The chemical constituents of the diet may possibly be responsible for the decline in the gastric acidity, but this is improbable because, after the third day of life, the infant as a rule has an adequate supply of normal food constituents to prevent a fall in the gastric acidity until the tenth day of life. Further, Nicol and Lyall (1939) have shown by numerous experiments, supported by others performed by other investigators, that when man is given a salt-deficient diet, and when the gastric secretion is continuously aspirated, there is no reduction in the sodium chloride or hydrochloric acid content of the gastric secretion.

The probable source of the gastrogenic substance or hormone is either the mother, through the placental circulation, or the placenta itself. Such a suggestion is not fantastic, for Ivy and Farrel (1925) as well as Lim and Necheles (1926) have convincingly demonstrated the existence of a gastric hormone in the blood of dogs, which has been shown to act on the cells of the gastric mucosa producing gastric juice.

\section{Correlation of birth weight with the gastric acidity and the development of the gastric mucosa at birth}

From the literature on the gastric acidity in infancy it is clear that almost all unfed infants have at birth free acid in their gastric secretion (Tangl, 1906; Hess, 1913; Pollitzer, 1921; and Griswald et al., 1925). The majority of the investigators did not make quantitative analyses, nor did they contrast the 
gastric secretion of the mature infant with that of the premature infant. It was therefore decided to make a comparison of the birth weight with the gastric secretion.

For this purpose the fasting juice was obtained from sixty-three mature infants and sixty-four premature infants within eight hours of birth and before they were fed. The specimens were tested for hydrochloric acid with Gunzburg's reagent, and if it was present, the free acidity was estimated by titrating it with $\mathrm{N} / 70 \mathrm{NaOH}$, using Töpfer's reagent as indicator. The results are shown in fig. 2, where the acidity is expressed in c.c. $\mathrm{N} / 10 \mathrm{HCl}$ per 100 c.c. gastric juice.

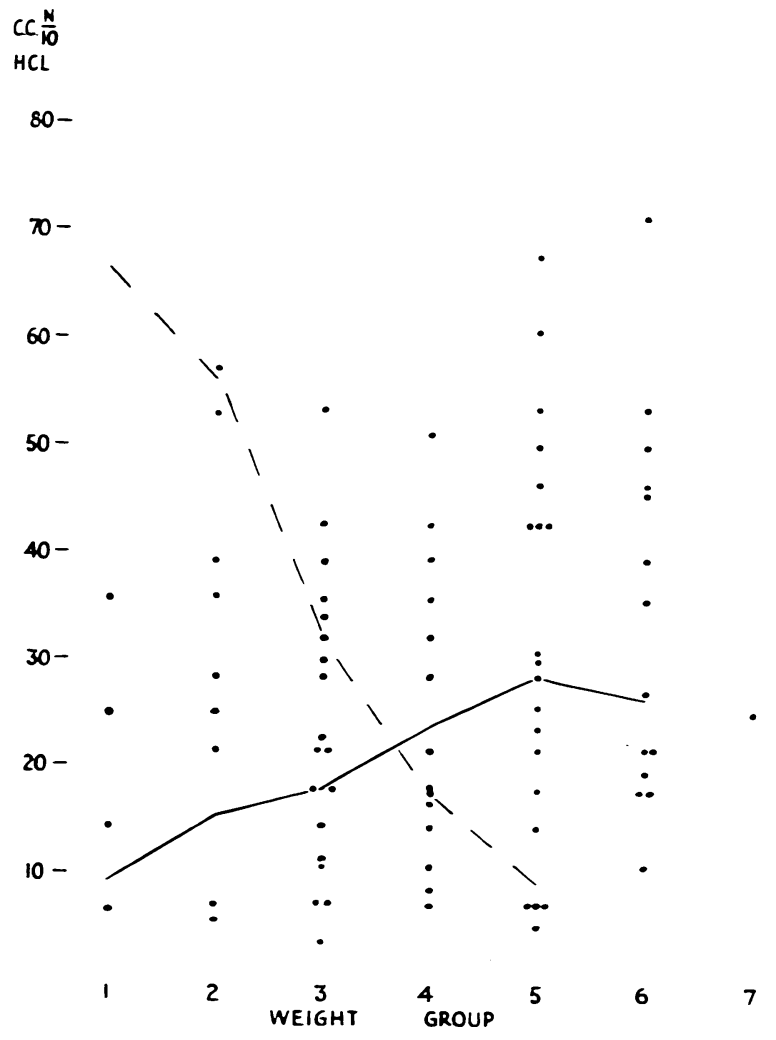

FIG. 2.-To show the effect of increase in birth weight upon the free acidity of the fasting juice. A continuous line demonstrates the average acidity for each weight group. The interrupted line represents the percentage of infants in each group with achlorhydria.

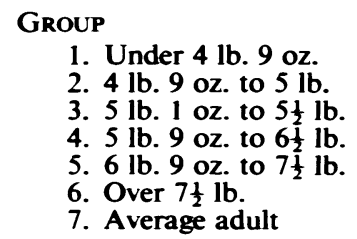

No. OF CASES

9

16

24

17

22

It will be observed that only eighty specimens are recorded in fig. 2 out of the 127 tested. This is owing to the fact that twenty-seven normal infants had an 
achlorhydria at birth and are therefore only represented by the interrupted line. The remaining twenty cases have been omitted because they were suffering from birth injury or disease such as asphyxia or cerebral haemorrhage or because their fasting juice contained bile or blood.

\section{Histological examination of gastric mucous membrane}

The state of development of the gastric mucosa was considered, since it was thought that it might explain the varying concentrations of the gastric acidity at birth and the rate of progress of the newborn infant. For this purpose ten stomachs were obtained from infants who died half an hour to eight days after birth. The infants' weights at birth were : 2 lb. 6 oz., 2 lb. 14 oz., 4 lb., 4 lb. 7 oz., 4 lb. 12 oz., 5 lb. 8 oz., 5 lb. 10 oz., 6 lb. $5 \frac{1}{2}$ oz., 7 lb. 4 oz., and $7 \mathrm{lb} .8 \mathrm{oz}$. The stomachs were fixed in formol-saline within half an hour of death, and afterwards sections were taken from the cardio-oesophageal junction, the fundus, the body and the pylorus. The sections were stained with haematoxylin and eosin; and an additional section of the fundus and the body was stained with methylene blue and eosin in order that the oxyntic cells might be seen more distinctly.

The microscopic findings were that in the three smallest infants the stomach mucous membrane was of a very primitive type; the glands were very shallow and loosely packed, and in the region of the fundus and body of the stomach, there were only a few oxyntic cells confined to the base of the glands (fig. 3).

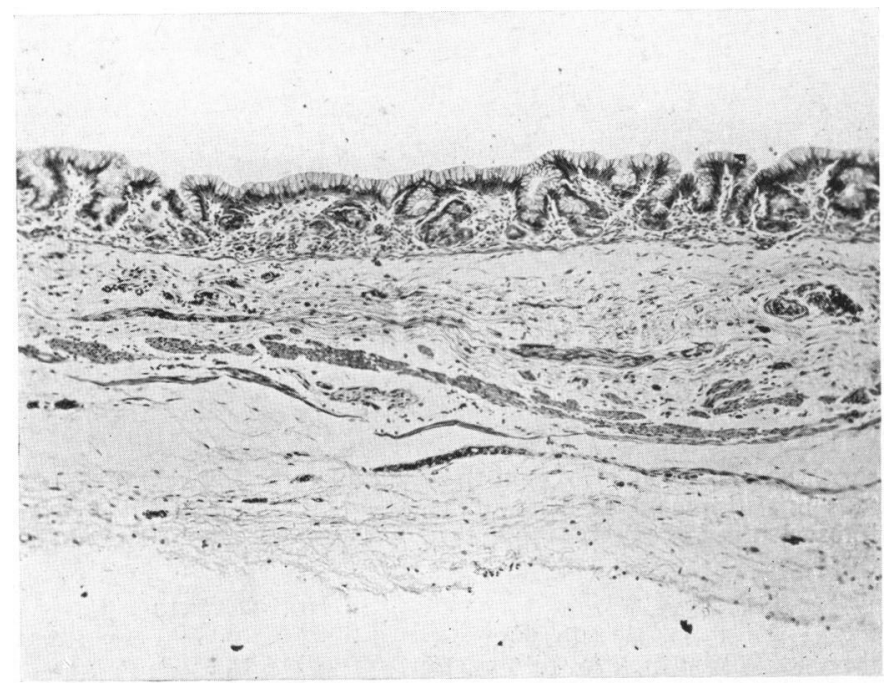

Fig. 3.-Microphotograph of fundus of stomach of infant $2 \mathrm{lb} .6 \mathrm{oz} .(\times 70)$.

Stomachs from infants of $4 \mathrm{lb} .7 \mathrm{oz}$. or more had well-developed glands with more numerous oxyntic cells, but these cells did not attain their maximum numbers until the infant's weight was $6 \mathrm{lb} .5 \mathrm{oz}$. or more. The oxyntic cells were then seen in the body of the glands as well as at their bases (fig. 4). There 


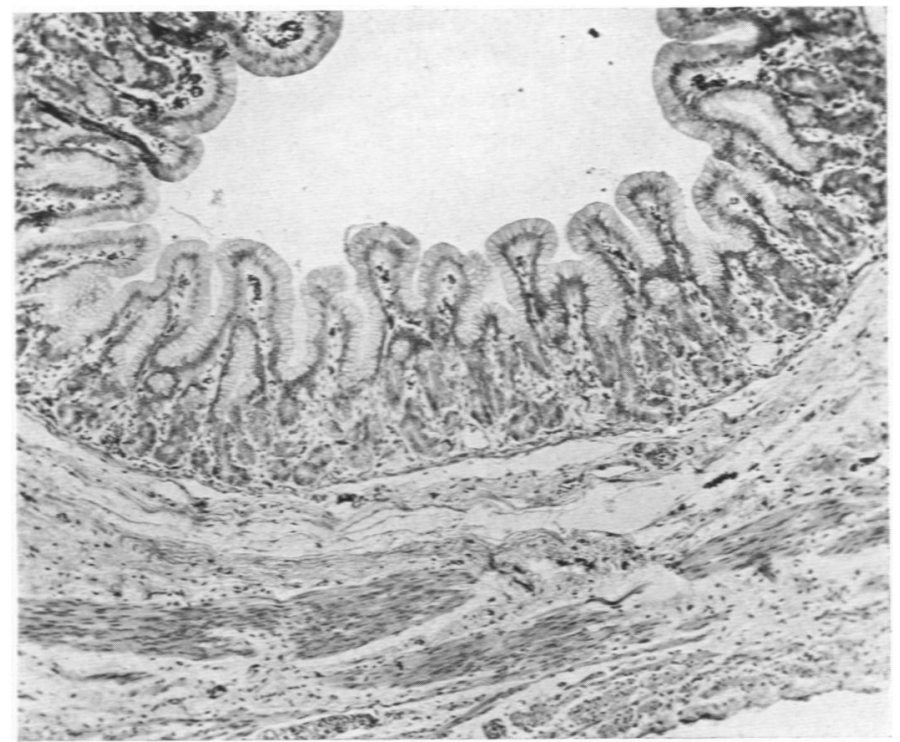

FIG. 4.-Microphotograph of fundus of stomach of infant $6 \mathrm{lb} .5 \frac{1}{2} \mathrm{oz} .(\times 70)$.

was, however, one stomach, belonging to the infant weighing $5 \mathrm{lb} .8 \mathrm{oz}$., which did not conform to the general finding that the heavier an infant is at birth the better is its gastric mucosa developed, for it was hypoplastic.

\section{Comment}

The INFLUENCE OF BIRTH WEIGHT. The biochemical and histological investigations show beyond doubt that the heavier an infant is at birth the more likely is it to have a more perfectly developed gastric mucous membrane and potent gastric secretion.

InCIDENCE OF ACHLORHYDRIA AND ITS CAUSATION. Contrary to the findings reported in the literature, achlorhydria in this series of cases occurred frequently, particularly with lower birth weights. It was also noted in ten out of thirteen infants suffering from cerebral haemorrhage. The occurrence of achlorhydria in the latter is not altogether surprising since diminution in the gastric secretion is associated with nutritional diseases, generalized infections and persistent vomiting (Stewart, 1937; Parsons, 1924, 1929; Salmi, 1937; and Steimann, 1936). A possible explanation of hypochlorhydria in the healthy infant is given by finding histologically one mature infant with a primitive gastric mucosa, and progressively more often with the fall in birth weight. Whether the hypoplasia tends to persist in the mature infants and results in the production of congenital achlorhydria is a matter for investigation.

\section{Summary}

1. Seven hundred and seven fasting juices were obtained from infants during the first month of life and tested for free and total acidity. The results are 
recorded and the average figures throughout the month have been given. From them it is clear that the gastric acidity falls during the first ten days of life and that thereafter it gradually rises. An explanation of this behaviour is discussed and it is suggested that there is a gastrogenic hormone transmitted from the the mother to the infant through the placental circulation. The incidence and causation of achlorhydria is mentioned and discussed.

2. Proof is given that the birth weight of the infant bears a close relationship to the amount of acid secreted by the stomach and to the degree of development of the gastric mucosa. For this purpose fasting juices from sixty-three mature infants and sixty-four premature infants were tested quantitatively for free acid. For the histological examination of the gastric mucosa, six stomachs from premature infants and four from mature infants were used. The specimens were carefully placed in fixative within half an hour of death and sections prepared later in the usual way.

Thanks are due to Professor Charles McNeil for his guidance and the close interest he has given in this work. Thanks are also due to Professor $\mathbf{R}$. W. Johnstone, Dr. W. F. T. Haultain, and Dr. Douglas Miller for permission to carry out the investigations in their wards; and to Dr. Agnes MacGregor for assistance in the histological investigations: and especially to Sister Taylor and the nursing staff for their co-operation in obtaining all the specimens.

\section{REFERENCES}

Block, P. W. (1936). Endocrinology, 20, 307.

Cutter, R. D. (1938). J. Pediat., 12, 1.

Davidsohn, H. (1921). Arch. Kinderheilk., 69, 147-229.

Faber, K. (1927). Lect. on Int. Med., New York.

Griswald, C., and Schohl, A. T. (1925). Amer. J. Dis. Child., 30, 543.

Hess, A. F. (1913). Ibid., 6, 264.

Ihre, B. J. E. (1939). Human Gastric Secretion, 1st edition, London, p. 99.

Ivy, A. C., and Farrel, J. I. (1925). Amer. J. Physiol., 74, 639.

Krahmer-Peterson, quoted by Ihre (1939), p. 118.

Levinson, S. A., and MacFate, R. P. (1937). Clinical Laboratory Diagnosis, Phila., 616.

Lim, R. K. S., and Necheles, H. (1926). Proc. Soc. exp. Biol., 24, 197.

Nicol, B. M., and Lyall, A. (1939). Lancet, 1, 144.

Parsons, L. G. (1924). Ibid., 1, 797. (1929). Proc. roy. Soc. Med., 31, 1043.

Pollitzer, R. (1921). Pediatria, Naples, 29, 253.

Salmi, T. (1937). Acta Paediatr., Stockh., 21, 362.

Steimann, W. (1936). Mschr. Kinderheilk., 65, 264.

Stewart, A. (1937). Brit. J. Child. Dis., 34, 1.

Strauss, M. B., and Castle, W. B. (1932). Amer. J. med. Sci., 184, 655.

Tangl, F. (1906). Pflüg. Arch. ges. Phisiol., 115, 64.

Weisman, A. I., Kleiner, I. S., and Allen, C. (1935). Endocrinology, 19, 393. 